\title{
Characterization of the planetary boundary layer height and structure by Raman lidar: comparison of different approaches
}

\author{
D. Summa ${ }^{1}$, P. Di Girolamo ${ }^{1}$, D. Stelitano ${ }^{1}$, and M. Cacciani ${ }^{2}$ \\ ${ }^{1}$ Scuola di Ingegneria, Università degli Studi della Basilicata, Viale dell'Ateneo Lucano n. 10, 85100 Potenza, Italy \\ ${ }^{2}$ Dipartimento di Fisica, Università degli Studi di Roma "La Sapienza" Piazzale Aldo Moro, 2, 00100 Rome, Italy
}

Correspondence to: D. Summa (donato.summa@unibas.it)

Received: 14 May 2013 - Published in Atmos. Meas. Tech. Discuss.: 13 June 2013

Revised: 24 October 2013 - Accepted: 25 October 2013 - Published: 10 December 2013

\begin{abstract}
The planetary boundary layer (PBL) includes the portion of the atmosphere which is directly influenced by the presence of the earth's surface. Aerosol particles trapped within the PBL can be used as tracers to study the boundarylayer vertical structure and time variability. As a result of this, elastic backscatter signals collected by lidar systems can be used to determine the height and the internal structure of the PBL.

The present analysis considers three different methods to estimate the PBL height. The first method is based on the determination of the first-order derivative of the logarithm of the range-corrected elastic lidar signals. Estimates of the PBL height for specific case studies obtained through this approach are compared with simultaneous estimates from the potential temperature profiles measured by radiosondes launched simultaneously to lidar operation. Additional estimates of the boundary layer height are based on the determination of the first-order derivative of the range-corrected rotational Raman lidar signals. This latter approach results to be successfully applicable also in the afternoon-evening decaying phase of the PBL, when the effectiveness of the approach based on the elastic lidar signals may be compromised or altered by the presence of the residual layer. Results from these different approaches are compared and discussed in the paper, with a specific focus on selected case studies collected by the University of Basilicata Raman lidar system BASIL during the Convective and Orographically-induced Precipitation Study (COPS).
\end{abstract}

\section{Introduction}

The planetary boundary layer (PBL) is the lower region of the atmosphere directly in contact with the earth's surface and strongly influenced by this surface. In this layer physical quantities such as flow velocity, temperature and moisture display rapid fluctuations associated with turbulent motion and vertical mixing.

The characterization of the planetary boundary layer is of primary importance in a variety of fields such as weather forecasting, climate change modelling and air quality prediction (Melfi et al., 1985; Flamant et al., 1997). The structure of the PBL can be complex and highly variable (Stull, 1988; Garratt, 1992). The PBL height is commonly used to characterize the vertical extent of mixing within the boundary layer and the height at which exchange with the free troposphere takes place (among others, Seibert et al., 2000).

Aerosol particles trapped within the PBL can be used as tracers to study the boundary-layer vertical structure and time variability. In fact, aerosols uplifted after sunrise by convective mixing can act as efficient tracers for the atmospheric portion over which mixing occurs (among others, Flamant et al., 1997). Aerosols can also be dispersed out of the PBL during strong convective events or temporary breaks of the capping temperature inversion. Thus, elastic backscattered signals from aerosol particles measured by lidar systems can be used to determine the height and internal structure of the PBL and, when possible, of the residual layer and aerosol layers within and aloft the PBL (Melfi et al., 1985; Di Girolamo et al., 1999).

Several methods have been applied to estimate the PBL height and structure and their variability from the elastic lidar 
backscatter signals in the presence of mixed, stable and residual boundary layers (Melfi et al., 1985; Boers et al., 1988; Flamant et al., 1997; Hayden et al., 1997; Di Girolamo et al., 1999; Seibert et al., 2000; Sicard et at., 2006). A widely used approach is based on the computation of the derivative of the elastic lidar backscatter signal (Russell et al., 1974; Menut et al., 1999; Bösenberg and Linné, 2002; Frioud et al., 2003; Matthias et al., 2004; Pal et al., 2010). An estimate of the PBL height can also be obtained from the elastic lidar signal variance (Hooper and Eloranta, 1986; Menut et al., 1999) or considering threshold signal levels (Melfi et al., 1985; Hayden et al., 1997; Steyn et al., 1999; Hoff et al., 1997; Hägeli et al., 2000; Cohn and Angevine, 2000; Davis et al., 2000; Brooks, 2003).

An alternative lidar approach is based on the application of a Haar wavelet covariance transform to lidar backscatter profiles to provide automated detection of the boundary layer top by locating the maximum in the covariance profiles (Mallat and Hwang, 1992; Brooks, 2003; Morille et al., 2007; Pal et al., 2010; Behrendt et al., 2011).

However, the complexity of the phenomena occurring within the PBL and the influence of advection and local accumulation processes in many cases prevent an unambiguous determination of the PBL height from elastic lidar signals, especially when aerosol stratifications are present within the PBL (Haeffelin et al., 2012).

A convenient, reliable and widely used approach for the determination of the boundary layer height and structure both in daytime and nighttime is represented by the identification of local maxima in the potential temperature vertical gradient profiles as measured by radiosondes (Cramer, 1972; Oke, 1988; Stull, 1988; Sorbjan, 1989; Garratt, 1992; Van Pul et al., 1994; De Wekker et al., 1997; Martucci et al., 2007; Behrendt et al., 2011). Specifically, potential temperature tends to keep nearly constant with height within the mixed layer. The level of the maximum vertical gradient in potential temperature indicates the transition from a convectively unstable region, located below this maximum, to a stable or more stable region, located above the maximum. The stable layer at the top of the mixed layer stops the turbulent eddies from further rising. Very stable layers characterized by increasing temperature values with height (called capping inversions) can keep deep convection from developing. During the day, the level at which air parcels become negatively buoyant corresponds to a main temperature inversion. Convection is often observed to erode this inversion, permitting the buoyant air parcel to lift further up. When turbulence weakens in the afternoon, the temperature inversion builds up again, and this translates into a narrowing of the mixing region.

However, a fraction of aerosols can remain aloft, with limited subsidence. In this situation, the strong aerosol gradient observed in the afternoons and after sunset is representative of a residual aerosol layer aloft the actual mixed layer. In these cases, the application of the approach to estimate the PBL height based on the use of the first-order derivative of the logarithm of the range-corrected elastic signals usually fails. The same is true for the approach based on the application of a Haar wavelet covariance transform to lidar backscatter profiles, as in fact after daytime convection ceases, aerosol layers may become stratified and multiple layers can form near the surface, thus preventing this algorithm from distinguishing the top of the boundary layer. In this situation alternative estimates of the PBL height can still be obtained from the rotational Raman lidar signals used for temperature measurements. This approach is introduced and tested for the first time in the present paper. As the residual layer height corresponds to a higher altitude temperature inversion (Martucci et al., 2010), the rotational Raman signals can potentially be used to infer both the mixed layer and the residual layer height.

Based on the above considerations, in the present work three different approaches to characterize the PBL height and structure are compared. The first approach is based on the application of the first-order derivative to the logarithm of the range-corrected elastic signals (in what follows specified as "approach (1)"). The second approach considers the application of the same algorithm to the low quantum number rotational Raman lidar signals, which are typically used for temperature measurements (in what follows specified as "approach (2)" or rotational Raman approach). Signals used in the application of these two approaches are provided by BASIL, which is a Raman lidar system with temperature measurement capability. Results from these two approaches are compared with simultaneous estimates from the traditional approach which considers local maxima in the potential temperature vertical gradient profiles measured by radiosondes. The analysis is applied to 10 selected case studies from the COPS experiment, which are characterized by different meteorological conditions.

The outline of the paper is the following: Sect. 2 provides a short description of the Raman lidar system BASIL, together with brief information on the COPS experiment and its observation strategy. In Sect. 3 a description of the different approaches is given, and the results are illustrated and compared. Finally, in Sect. 4 all results are summarized.

\section{BASIL}

The University of BASILicata Raman Lidar system (BASIL) was deployed in Achern (Black Forest, Germany, lat: $48.64^{\circ} \mathrm{N}$, long: $8.06^{\circ} \mathrm{E}$, elev.: $140 \mathrm{~m}$ ) in the frame of the Convective and Orographically-induced Precipitation Study - COPS (Wulfmeyer et al., 2008, 2011). The COPS experiment was held in southern Germany and eastern France in the period 1 June-31 August 2007, as part of the German Research Foundation (DFG) Priority Programme 1167 "Quantitative Precipitation Forecast", with the overarching goal of advancing the quality of forecasts of orographically 
induced convective precipitation by four-dimensional observations and modelling of its life cycle (Kottmeier et al., 2008; Kalthoff et al., 2009; Wulfmeyer et al., 2011). During COPS, BASIL operated between 25 May and 30 August 2007 and collected more than $500 \mathrm{~h}$ of measurements, distributed over 58 measurement days and 34 intensive observation periods (IOPs). Quicklooks of these data sets are available on the COPS website (http://www.cops2007.de/), under "Operational Products", while water vapour and particle backscatter data for the most important IOPs can be downloaded from the World Data Center for Climate (http://cera-www.dkrz.de/ WDCC/ui/BrowseExperiments.jsp?proj=COPS). All other COPS data from BASIL can be directly requested from the authors of this paper.

The major feature of BASIL is represented by its capability to perform high-resolution and accurate measurements of atmospheric temperature and water vapour, both in daytime and nighttime, based on the application of the rotational and vibrational Raman lidar techniques in the UV (Di Girolamo et al., 2004, 2006, 2009a; Bhawar et al., 2011). Besides temperature and water vapour, BASIL provides measurements of the particle backscattering coefficient at 355, 532 and $1064 \mathrm{~nm}$, of the particle extinction coefficient at 355 and $532 \mathrm{~nm}$ and of particle depolarization at 355 and $532 \mathrm{~nm}$ (Griaznov et al., 2007; Di Girolamo et al., 2009b, 2012a, b; Maestri et al., 2010; Griaznov et al., 2007). A block diagram of the considered system is illustrated in Fig. 1. COPS measurement strategy considers a transect of five supersites from the Vosges Mountains to the lee side of the Black Forest, crossing the Rhine Valley, the Hornisgrinde Mountain and the Murg Valley. During COPS BASIL was located in the Rhine Valley supersite (supersite R). A variety of sensors were present in all supersites: moisture sensors, turbulence or energy balance stations, radiosonde launching facilities, GPS tomography, and surface meteorological stations; most supersites were also equipped with lidars, radars and microwave radiometers. The variety of remote-sensing systems at each supersite and the potential synergistic use of those is a peculiar aspect of the COPS experiment (Wulfmeyer et al., 2008).

\section{Results}

The algorithm which is considered in this paper to estimate the PBL height from the Raman lidar data considers the following quantity:

$$
D(z)=\frac{d}{\mathrm{~d} z}\left(\ln \left[P_{\lambda}(z) z^{2}\right]\right),
$$

where $P_{\lambda}(z)$ is either the elastic lidar backscatter signal at $1064 \mathrm{~nm}, P_{\lambda_{\mathrm{El}}}(z)$ ), (considered in approach (1)) or the low quantum number rotational Raman lidar signal, $P_{\lambda_{\mathrm{LOJ}}}(z)$, (considered in approach (2)), and the quantity $P_{\lambda}(z) z^{2}$ represents the range-corrected lidar signal. In the application of

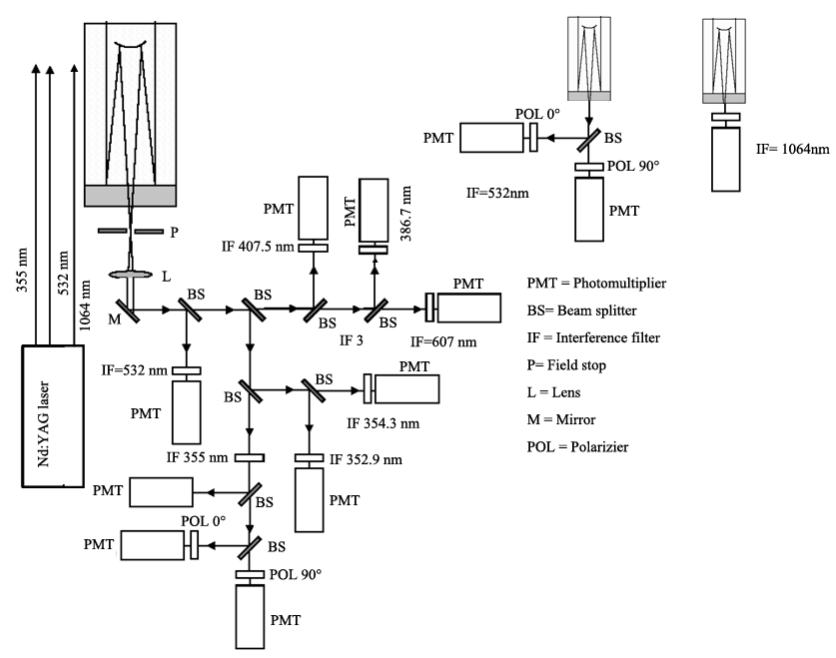

Fig. 1. Block diagram of the set-up of the Raman lidar system BASIL during COPS.

Eq. (1), different integration times are considered for $P_{\lambda_{\mathrm{El}}}(z)$ and $P_{\lambda_{\mathrm{LOJ}}}(z)$. Specifically, an integration time of $10 \mathrm{~min}$ is considered for $P_{\lambda_{\mathrm{El}}}(z)$, while an integration time of $30 \mathrm{~min}$ is considered for $P_{\lambda_{\mathrm{LOJ}}}(z)$, this latter being characterized by smaller signal-to-noise ratios.

When elastic signals are used, the minima of the quantity $D(z)$ identify the transitions between different layers, with the largest minimum usually identifying the boundary layer height. This approach is identified hereafter as "approach (1)" when applied to elastic lidar signals at $1064 \mathrm{~nm}$, while it is identified as "approach (2)" or rotational Raman approach when applied to the low quantum number rotational Raman lidar signals. For the purpose of this study, "approach (1)" was applied to the elastic lidar backscatter signals at $1064 \mathrm{~nm}$ instead of the elastic lidar backscatter signals at 532 and $355 \mathrm{~nm}$ because of the larger sensitivity of the former signals to aerosols and their variability.

Potential temperature profiles, $T_{\text {pot }}(z)$, obtained from the radiosonde data were also used to get additional estimates of the boundary layer height. This approach considers the maximum in the derivative of $T_{\text {pot }}(z)$, which identifies the height of maximum gradient.

As already emphasized earlier, approach (2) is introduced and tested for the first time in the present paper. In this respect, we need to recall that temperature measurements are performed by BASIL through the application of the rotational Raman lidar technique in the UV, this technique being based on the detection of pure rotational Raman scattering from oxygen and nitrogen molecules. These rotational lines fall within two narrow spectral bands in the proximity of the laser wavelength: one including lines characterized by low quantum rotational numbers, $P_{\lambda_{\text {LoJ }}}(z)$, and the other including lines characterized by high quantum rotational numbers, $P_{\lambda_{\text {HiJ }}}(z)$. Atmospheric temperature measurements can 
be obtained from the power ratio of high to low quantum number rotational Raman lidar signals. Both $P_{\lambda_{\text {LoJ }}}(z)$ and $P_{\lambda_{\mathrm{HiJ}}}(z)$ are characterized by a strong sensitivity to temperature variations, the sensitivity being anyhow larger for the signal $P_{\lambda_{\mathrm{HiJ}}}(z)$ than for $P_{\lambda_{\mathrm{LOJ}}}(z)$. It is worth pointing out, however, that $P_{\lambda_{\text {LoJ }}}(z)$ is usually affected by a smaller random uncertainty than $P_{\lambda_{\mathrm{HiJ}}}(z)$, as a result of both the smaller cross section of the high quantum number rotational Raman lines and the larger bandwidth of the interference filter used for the selection of these lines. The larger random uncertainty affecting $P_{\lambda_{\text {HiJ }}}(z)$ often prevents from obtaining accurate PBL height estimates based on the application to this signal of approach (2), especially in the central portion of the day, when solar irradiance is higher and has larger effects on the noise level of the signal. Thus, in approach (2), Eq. (1) is applied to the rotational Raman signal $P_{\lambda_{\text {LoJ }}}(z)$. Nevertheless, we tested this approach also with $P_{\lambda_{\text {HiJ }}}(z)$, and corresponding results are included in Fig. $4 \mathrm{~b}$.

We need to recall at this point that, while approach (1) allows the estimation of the PBL height based on the identification of the elastic lidar signal gradients associated with gradients in particle backscatter at the top of the PBL (with aerosols acting as atmospheric dynamical tracers), approach (2) allows obtaining PBL height estimates based on the identification of the rotational Raman lidar signal gradients, primarily associated with the temperature gradients found at the top of the boundary layer, which characterize the transition from the convectively unstable region within the PBL to the more stable region aloft.

It is worth pointing out that both the low and the high quantum number rotational Raman signals are dependent on both temperature and molecular/particle extinction. However, vertical changes in molecular extinction are very smooth with limited effects on rotational Raman signal gradients, while the sensitivity of rotational Raman signals to temperature gradients is much larger than their sensitivity to particle extinction gradients. In this respect, it is to be specified that typical temperature gradients observed at the top of the boundary layer $\left(0.03-0.05 \mathrm{~K} \mathrm{~m}^{-1}\right)$ lead to low/high quantum number rotational Raman signal gradients which are a factor of 2-5/10-50 larger than those associated with the typical particle extinction gradients observed at the top of the boundary layer $\left(2-3 \times 10^{-8} \mathrm{~m}^{-1} \mathrm{~m}^{-1}\right)$. Based on this consideration, we can state that this technique is primarily sensitive to temperature gradients and far less to particle and total extinction gradients. This aspect makes the approach particularly effective and useful in the determination of the PBL height as it results to be successfully applicable also in the afternoon-evening decaying phase of the PBL, when the effectiveness of the approach based on the use of the elastic backscatter lidar signals may be compromised or altered by the presence of the residual layer. Additionally, this approach allows an unambiguous determination of the PBL height also in the presence of aerosol stratifications within the PBL.
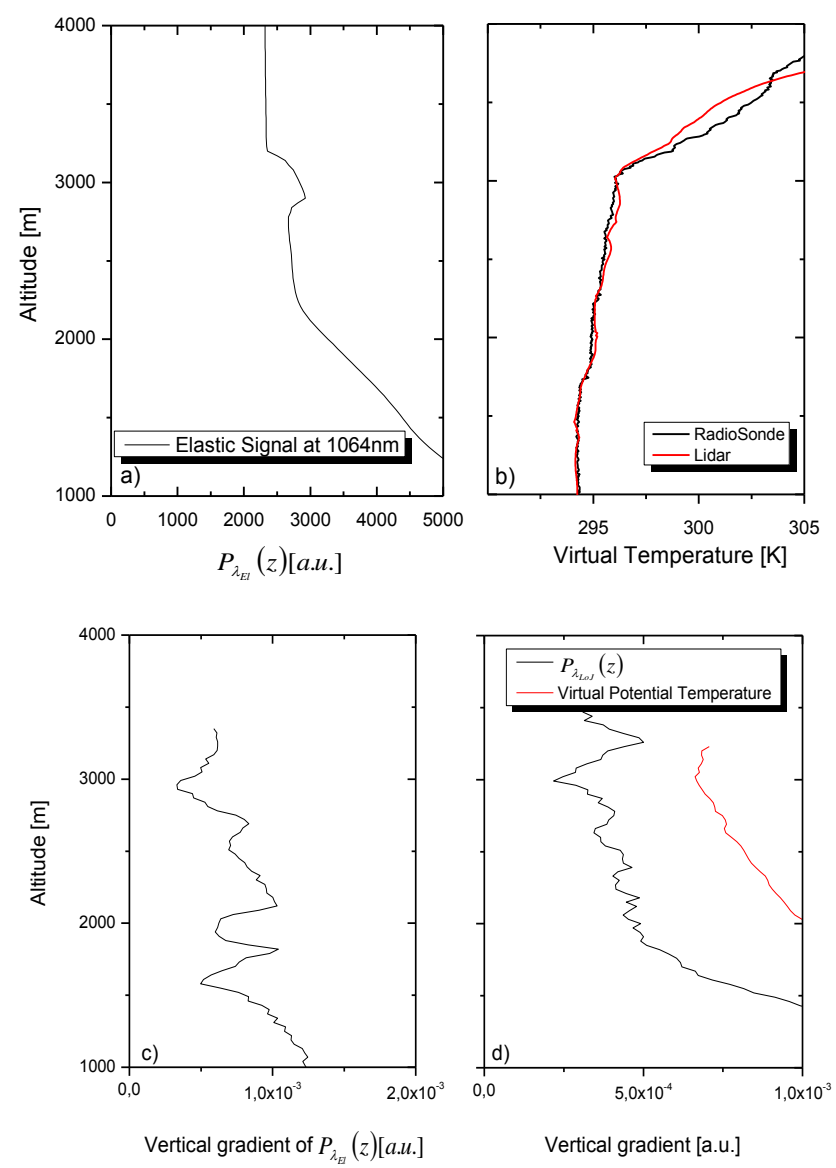

Fig. 2. (a) $10 \mathrm{~min}$ average profile of $P_{\lambda_{\mathrm{El}}}$ (z) centred at 17:04 UTC on 30 July 2007 as measured by BASIL. (b) vertical profiles of virtual potential temperature as measured by BASIL and the radiosonde (RS) launched at 17:04 UTC. (c) vertical gradient of $P_{\lambda_{\mathrm{El}}}(z)$ for the same $10 \mathrm{~min}$ time interval considered in (a). (d) vertical gradient of $P_{\lambda_{\text {Loj }}}(z)$ and the virtual potential temperature gradient lidar measurement for the same 10 min time interval considered in (a). The dashed lines in all panels identify the PBL height.

It is also worth pointing out that the direct use of the lidar measurement of the temperature gradient would have certainly been a valid alternative to approach (2) (see following discussion of Fig. 2). However, the determination of the temperature profiles from the rotational Raman signals, and consequently their gradients, would have implied the use of a more complex analysis scheme, requiring the application of a dedicated calibration procedure. Furthermore, we wished to verify the possibility of extending to the rotational Raman signals the same simple algorithm applied to the elastic backscatter signals (identification of the minima in the derivative of the logarithm of the lidar signals).

Figure 2 shows the variability of the different quantities considered in the three approaches. Specifically, Fig. 2a illustrates the $10 \mathrm{~min}$ average profile of $P_{\lambda_{\mathrm{El}}}(z)$ centred at 17:04 UTC on $30 \mathrm{July}$, which reveals the presence of a strong gradient around $3000 \mathrm{~m}$, corresponding to the 
temperature inversion simultaneously observed by the radiosonde (launched at 17:04 UTC) and by the lidar system (Fig. 2b). Figure 2c illustrates the vertical gradient of $P_{\lambda_{\mathrm{El}}}(z)$ for the same $10 \mathrm{~min}$ time interval considered in Fig. 2a, while Fig. $2 \mathrm{~d}$ illustrates the vertical gradient of $P_{\lambda_{\mathrm{LoJ}}}(z)$ and of the virtual potential temperature gradient lidar measurement for this same time interval. The vertical gradient profiles in Fig. 2c-d reveal the presence of the subsequent minima, identifying the transitions between the different aerosol layers, and specifically the presence of the largest minima, which are used to identify the PBL height (dashed line). Figure $2 \mathrm{~d}$ also compares approach (2) with the approach based on the estimate lidar temperature gradient, revealing the exact co-location of the minima of these two quantities and consequently the very agreement of the two PBL height estimates.

We preliminary tested these approaches on three selected case studies (15, 26 and 30 July 2007), but we then extended the analysis to additional case studies (10 in total) covering a variety of boundary layer conditions (see Table 1). Figure 3a illustrates the time evolution of the particle backscattering ratio at $1064 \mathrm{~nm}, R_{1064}(z)$, on 15 July 2007 covering the time interval from 04:50 to 20:30 UT. Figure $3 \mathrm{~b}$ illustrates the time evolution of $R_{1064}(z)$ on 26 July 2007 covering the time interval from 04:50 to 14:15 UT, while Fig. 3c illustrates the time evolution of $R_{1064}(z)$ on 30 July covering the time interval from 07:15 to 19:45 UT. The black line in Fig. 3a and $b$ represents the PBL height as determined through the application of approach (1). In Fig. 3c the black line identifies the PBL height as determined through the application of approach (2), while the red line identifies its estimate in the evening and night portion of the measurement record as determined through approach (1). In the final portion of Fig. 3c, the PBL height estimates from approach (1) and (2) are found to differ, as in fact approach (2) properly identifies the PBL height, while approach (1) infers the residual layer height which is left behind after the decay of the convective activity. This aspect is further stressed in the forthcoming discussion of Fig. 4b.

Figure 4 illustrates the evolution of the boundary layer height as obtained from approach (1) and (2) and the radiosonde data for the three case studies on 15, 26 and 30 July 2007. In the figure the continuous lines identify the estimates obtained from approach (1), the yellow stars represent the estimates obtained from the radiosonde potential temperature profiles and the black squares represent the estimates obtained from approach (2). The figure covers the complete cycle of the PBL evolution including the transitions between day and night and between night and day. For all three cases the PBL height is found to grow during the day, reaching a maximum value in the early afternoon and then decaying in the late afternoon and evening.

For the purpose of the application of approaches (1) and (2), the signals $P_{\lambda_{\mathrm{EI}}}(z)$ and $P_{\lambda_{\mathrm{LOJ}}}(z)$ were integrated in time (over a period of $10 \mathrm{~min}$ for the former and over a period of

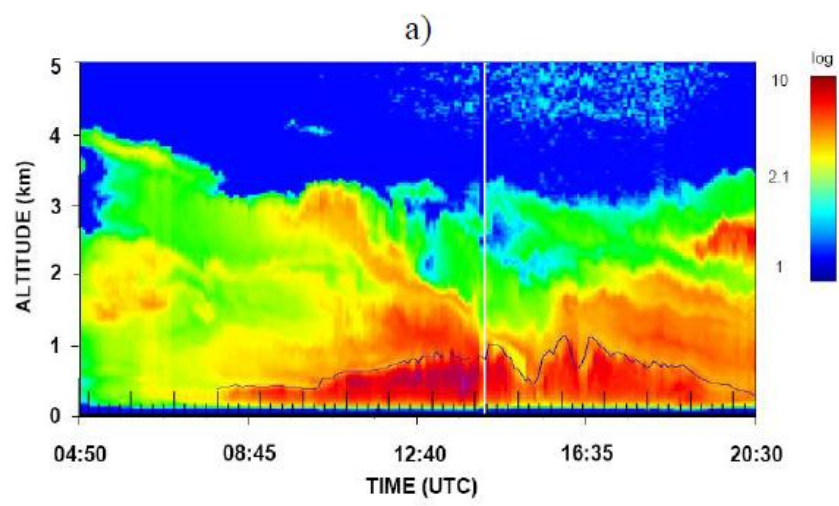

b)

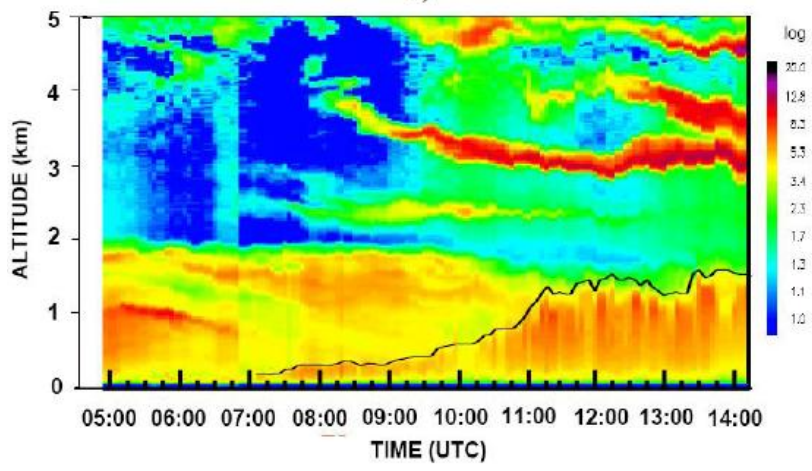

c)

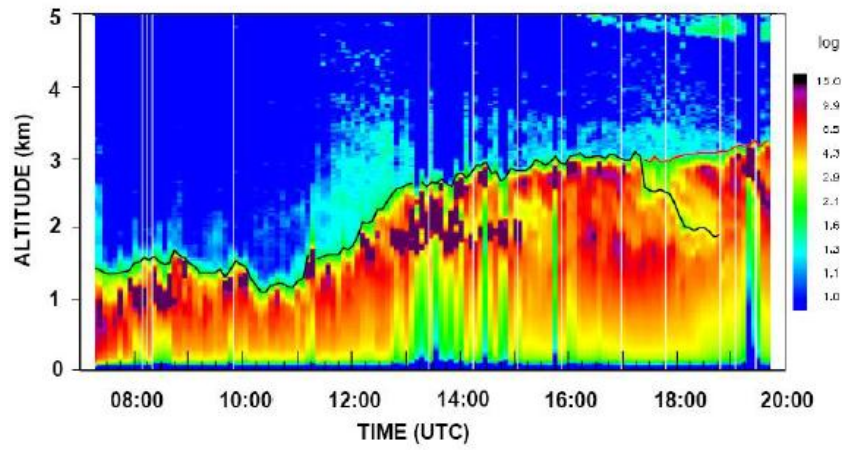

Fig. 3. Time evolution of the particle backscattering ratio at $1064 \mathrm{~nm}$ as measured by BASIL from 04:50 to 20:30 UT on 15 July 2007 (a); from 05:00 to 14:15 UT on 26 July 2007 (b) and from 07:15 to 19:45 UT on 30 July 2007 (c). In (a) and (b) the black line identifies the PBL height as determined through the application of approach (1); in (c) the black line identifies the PBL height as determined through the application of approach (2), while the red line identifies the residual layer height in the evening and night portion of the measurement session as determined through the application of approach (1) 
Table 1. List of the considered case studies with a description of the weather conditions.

\begin{tabular}{lll}
\hline Date(s) & IOP & Weather conditions \\
\hline 19 Jun 2007 & IOP4 & Shallow convection, shower during the day \\
15 Jul 2007 & IOP8 & Shallow convection, no precipitation \\
19 Jul 2007 & IOP9 & MCS moving over COPS region followed by partially convective precipitation \\
25 Jul 2007 & IOP11 & Cumulus convection mostly over the mountains \\
26 Jul 2007 & IOP11b & Cumulus convection \\
30 Jul 2007 & IOP12 & Cumulus convection \\
1 Aug 2007 & IOP13 & Cloud-free weather under a high-pressure ridge; Saharan dust over COPS domain \\
6 Aug 2007 & IOP14 & Isolated storm over the entire COPS domain followed by a large area of elevated precipitation \\
12 Aug 2007 & IOP15 & Storm over the eastern Black Forest and Swabian Jura \\
14 Aug 2007 & NO IOP & Clear air convection, shallow convection resulting from weak mid/upper-level ridging, cirrus and \\
& & altocumulus present during the day in response to warm advection \\
\hline
\end{tabular}
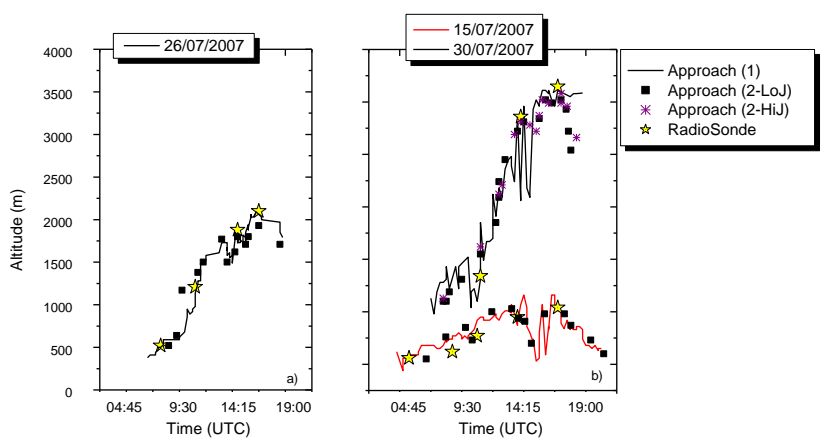

Fig. 4. Evolution of the PBL height for 15, 25 and 30 July 2007. The continuous lines identify the PBL height estimates obtained from approach (1). The yellow stars represent estimates obtained from the potential temperature profiles as measured by the radiosondes, and the blue squares represent the estimates obtained from approach (2). In (b), the red stars represent the estimates of the PBL height obtained with approach (2) applied to $P_{\lambda_{\mathrm{HiJ}}}(z)$.

$30 \mathrm{~min}$ for the latter) and vertically (applying a running average with a vertical window of $90 \mathrm{~m}$ over data points separated by $30 \mathrm{~m}$ steps). This allowed the reduction of signal statistical fluctuations which could affect the applicability of these approaches. Results in Fig. 4 reveal a very good agreement between the different approaches. In all three cases, with only one exception (i.e. the final portion of Fig. 4b), deviations between the PBL height estimates from the three different approaches are typically found not to exceed $200 \mathrm{~m}$. In the final portion of Fig. 4b, approach (1) is found to overestimate the PBL height, with deviations between approach (1) and (2) as large as 500-600 m. As already anticipated above, the failure of approach (1) is caused by the presence of a strong aerosol gradient above the actual mixed layer associated with the presence of a residual layer. In this specific case, approach (2) is still capable of properly estimating the PBL height, thus overcoming the limitations associated with the use of the elastic lidar backscatter signals. The red stars

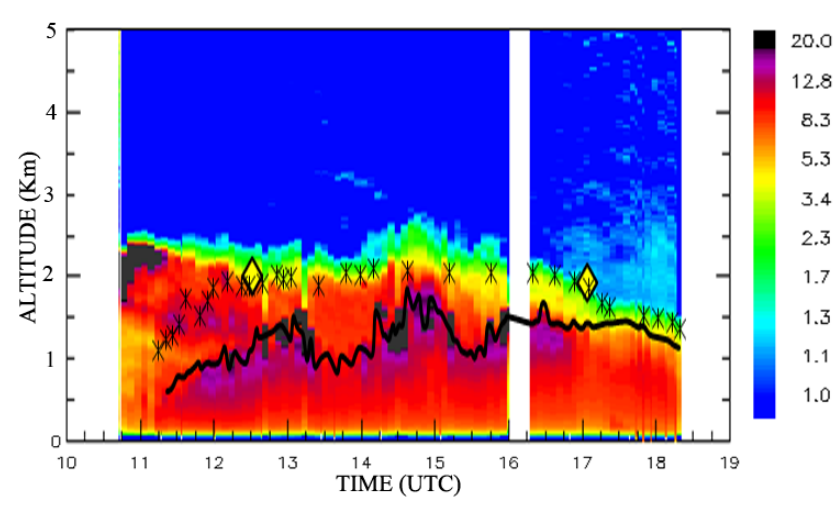

Fig. 5. Time evolution of the particle backscattering ratio at $1064 \mathrm{~nm}$ as measured by BASIL from 10:45 to 18:22 UT on $14 \mathrm{Au}-$ gust 2007. The black line represents the output of approach (1), the black stars represent the output of approach (2) and the yellow diamonds are the PBL height estimates obtained from the radiosonde potential temperature data.

in Fig. $4 \mathrm{~b}$ represent the PBL height estimates obtained from approach (2) applied to the high quantum number rotational signals $P_{\lambda_{\mathrm{HiJ}}}(z)$, these estimates being in very good agreement with those obtained with the application of approach (2) to $P_{\lambda_{\text {LoJ }}}(z)$.

As mentioned above, approach (1) is also found to fail in the presence of multiple aerosol layers within the PBL. This situation is represented in Fig. 5, illustrating the evolution of $R_{1064}(z)$ on 14 August 2007 over the time interval 10:45-18:22 UT; here the black line represents the output of approach (1), the black stars represent the output of approach (2) and the yellow diamonds are the PBL height estimates obtained from the radiosonde potential temperature data. In the time period till approximately 17:00 UT, as a result of the presence of a marked aerosol layer within the PBL in the altitude region $0.5-1.5 \mathrm{~km}$, occasionally topped with clouds, approach (1) returns false values of the PBL height, which result to be lower than those estimated by 

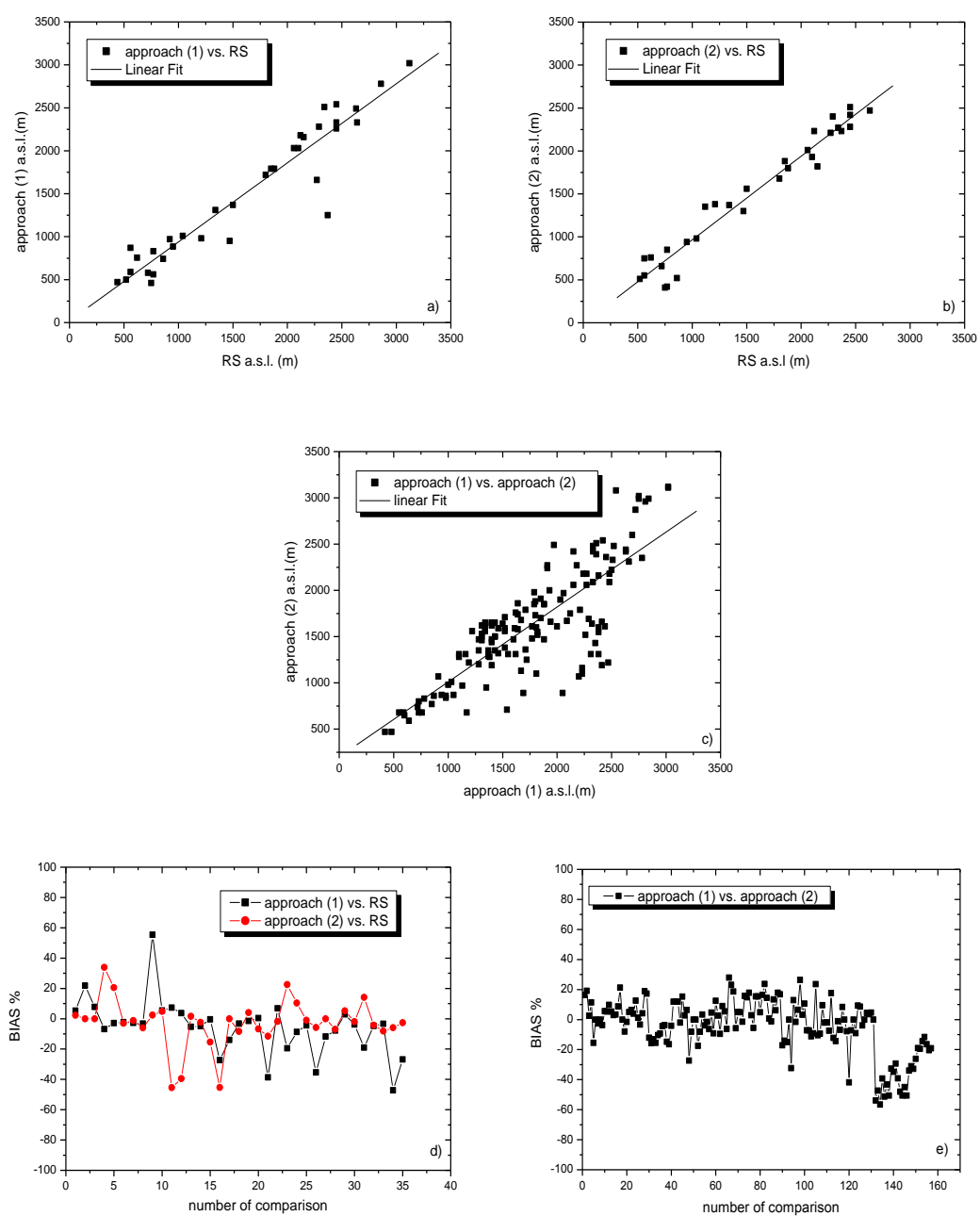

Fig. 6. Comparison of PBL height estimates obtained with different approaches: (a) approach (1) versus simultaneous radiosonde estimates; (b) approach (2) versus simultaneous radiosonde estimates; (c) approach (1) versus approach (2); (d) bias (expressed in \%) of approach (1) vs. radiosonde estimates (squares) and of approach (2) vs. radiosonde estimates (circles). (e) bias (expressed in \%) of approach (1) vs. approach (2). In (a)-(c) best fit lines are also included.

approach (2) and from the radiosonde data, with deviations between approach (1) and the other two approaches as large as $1 \mathrm{~km}$. The failure of approach (1) due to the algorithm revealing as the maximum gradient the one associated with the presence of the aerosol layer within the PBL instead of the one associated with the PBL top.

The approaches described above have been tested on several case studies to verify their applicability in different meteorological conditions, characterized by the presence of convective boundary layers generated both in clear-sky conditions and embedded in frontal activity (see Table 1 for a complete list of the selected cases). Figure 6 compares the PBL height estimates obtained through the three different approaches and includes results from all considered case studies (10 in total). Panel a of this figure compares the PBL height estimates obtained with approach (1) versus the simultaneous radiosonde estimates, while panel b compares the PBL height estimates obtained with approach (2) versus the simultaneous radiosonde estimates. Finally, panel c of this same figure compares the PBL height estimates obtained with approach (1) versus those obtained with approach (2).

Best fit lines are also included in panel a-c based on the application of a least-square fit analysis. The correlation coefficients, $R$, for these fitting lines are $0.95,0.98$ and 0.82 , respectively, while their slopes are $0.92,0.98$ and 0.81 , respectively. Values of the correlation coefficients are found to be large for all three comparisons, which testifies the high reliability and reproducibility of the two lidar-based approaches. The mean statistical parameters (correlation coefficient, standard deviation, number of comparisons and the coefficients of the linear regression) for all case studies are reported in Table 2. The slope value of 0.92 in Fig. 6a testifies a slight negative bias (8\%) of approach (1) with respect to the traditional approach based on the radiosonde potential 
Table 2. Mean statistical parameters for the comparisons involving the different methods. The different columns list the approach, the correlation coefficient, the standard deviation, $\sigma$, the ensemble of data (including the number of comparisons), the coefficients of the linear regression.

\begin{tabular}{|c|c|c|c|c|}
\hline Approach & $R$ & $\sigma(\mathrm{m})$ & Ensemble of data & $Y=A \times X+B$ \\
\hline Approach (1) vs. RadioSonde & 0.95 & 240 & All cases (number of comparisons: 36 ) & $\mathrm{A}=0.92+0.05 ; \mathrm{B}=19.2$ \\
\hline Approach (2) vs. RadioSonde & 0.98 & 160 & All cases (number of comparisons: 36 ) & $\mathrm{A}=0.98+0.04 ; \mathrm{B}=-10.4$ \\
\hline Approach (1) vs. approach (2) & 0.82 & 320 & All cases (number of comparisons: 160 ) & $\mathrm{A}=0.81+0.04 ; \mathrm{B}=200.4$ \\
\hline Approach (1) vs. RadioSonde & 0.97 & 150 & All cases except 14 August 2007 (number of comparisons: 34) & $\mathrm{A}=1.04+0.03 ; \mathrm{B}=59.16$ \\
\hline Approach (2) vs. RadioSonde & 0.98 & 160 & All cases except 14 August 2007 (number of comparisons: 32) & $\mathrm{A}=0.98+0.03 ; \mathrm{B}=71.1$ \\
\hline Approach (1) vs. approach (2) & 0.93 & 210 & All cases except 14 August 2007 (number of comparisons: 130) & $\mathrm{A}=0.93+0.02 ; \mathrm{B}=53.5$ \\
\hline Approach (1) vs. RadioSonde & 0.98 & 160 & $\begin{array}{l}\text { All cases except } 14 \text { August } 2007 \text { and data points after sunset } \\
\text { (number of comparisons: 30) }\end{array}$ & $\mathrm{A}=0.97+0.03 ; \mathrm{B}=60.5$ \\
\hline Approach (2) vs. RadioSonde & 0.97 & 160 & $\begin{array}{l}\text { All cases except } 14 \text { August } 2007 \text { and data points after sunset } \\
\text { (number of comparisons: } 30 \text { ) }\end{array}$ & $\mathrm{A}=0.98+0.03 ; \mathrm{B}=72.1$ \\
\hline Approach (1) vs. approach (2) & 0.94 & 210 & $\begin{array}{l}\text { All cases except } 14 \text { August } 2007 \text { and data points after sunset } \\
\text { (number of comparisons: 120) }\end{array}$ & $\mathrm{A}=0.97+0.03 ; \mathrm{B}=15.5$ \\
\hline
\end{tabular}

temperature profiles, while the slope value of 0.98 in Fig. $6 \mathrm{~b}$ testifies a slightly smaller negative bias (2\%) of approach (2) with respect to the radiosonde estimate. Also approach (1) and (2) are in fairly good agreement, with a relative bias between the two of $19 \%$ (slope value of 0.81 in Fig. 6c). Values of the mean standard deviation $(\sigma)$ for the PBL height estimates obtained from the compared approaches are found not to exceed $250 \mathrm{~m}$ for all comparisons (with the only exception of the comparison of approach (1) vs. approach (2), which is primarily affected by the presence of the data points from 14 August; see Table 2).

Panel d of Fig. 6 illustrates the bias (expressed in \%) of approach (1) vs. the radiosonde estimates and the bias of approach (2) vs. the radiosonde estimates, while panel e illustrates the bias (expressed in \%) of approach (1) vs. approach (2). Most bias values (>80\%) are found not to exceed $20 \%$, for the three comparisons, with the largest bias values found on 14 August and after sunset for the comparisons involving approach (1).

The agreement between approach (1) and the other two approaches increases in case the data points corresponding to the case study on 14 August 2007 (the one with the largest disagreement between approach (1) and the other two approaches as a result of the presence of an internal aerosol layer within the PBL) are removed from the statistical analysis. Specifically, the correlation coefficient $R$ for approach (1) vs. the radiosonde estimates gets a value of 0.97 (with a slope value of 1.04 , i.e. a relative bias of $4 \%$ ), $R$ for approach (2) vs. the radiosonde estimates keeps a value of 0.98 (with a slope value of 0.98 , i.e. a relative bias of $2 \%$ ), while $R$ for approach (1) vs. approach (2) gets a value of 0.93 (with a slope value of 0.93 , i.e. a relative bias of $7 \%$ ). It is to be noticed that, in case the data points corresponding to the case study on 14 August 2007 are removed, the best fit analyses including approach (1) are characterized by larger values of $R$ and slope values closer to 1 (i.e. lower bias).
The agreement between approach (1) and the other two approaches also increases in case the data points after sunset are removed from the statistical analysis. Specifically, $R$ for approach (1) vs. the radiosonde data gets a value of 0.98 (with a slope value of 0.97 , i.e. a relative bias of $3 \%$ ), $R$ for approach (2) vs. the radiosonde estimates keeps a value of 0.98 (with a slope value of 0.98 , i.e. a relative bias of $2 \%$ ), while $R$ for approach (1) vs. approach (2) gets a value of 0.94 (with a slope value of 0.97 , i.e. a relative bias of $3 \%$ ). Again, best fit analyses including approach (1) are characterized by larger values of $R$ and slope values closer to 1 (i.e. lower bias). All new statistical parameters are included in Table 2.

These results clearly reveal that, in the presence of multiple aerosol layers within the PBL or a residual layer aloft the PBL, approach (2) allows overcoming the limitations associated with the application of approach (1) and the use of the elastic backscatter lidar signals.

Finally, we wish to point out that neither approach (1) nor approach (2) can be considered to be preferable, each of the two having specific advantages and disadvantages. In general, in the daytime convective portion of the day, approach (1) should be preferred to approach (2) as in fact the former approach leads to more accurate estimates of the PBL height as a result of the smaller random error affecting the strong elastic signals with respect to the rotational Raman signals. However, after sunset or in the presence of marked aerosol layers within the PBL, approach (2) is to be preferred for its unambiguous response. The possibility of applying these two approaches together is certainly a big plus of the considered ground-based Raman lidar system.

\section{Conclusions}

The present work compares estimates of the PBL height as obtained from three distinct approaches applied to selected case studies from the COPS experiment. The first 
approach (called "approach (1)") considers a method based on the identification of minima in the first-order derivative of the logarithm of the range-corrected elastic lidar signals. Potential temperature profiles obtained from the radiosondes launched simultaneously to lidar operation are also used to get additional estimates of the boundary layer height, based on the widely used method which considers the transition from a convectively less stable region below the PBL top to a more stable region above (identified by the level of the maximum vertical gradient). Additional estimates of the boundary layer height are obtained from the identification of minima in the first-order derivative of the logarithm of the range-corrected rotational Raman lidar signals (called "approach (2)" or rotational Raman approach), tested for the first time in this paper.

These approaches have been applied to a variety of case studies characterized by different meteorological conditions. A good agreement is found between the three approaches, with the correlation coefficients of the fitting lines representing the comparisons between these approaches being always larger than 0.8. A small negative bias $(8 \%)$ is observed between approach (1) and the potential temperature approach, while a slightly smaller negative bias $(2 \%)$ is found between approach (2) and the potential temperature approach. A good agreement is also found between approach (1) and (2), with a relative bias between the two of $19 \%$. The good agreement between these different approaches supports us on their applicability in different meteorological conditions.

Furthermore, agreement between approach (1) and (2) and between approach (1) and the radiosonde estimate of the PBL height is found to increase if data points after sunset or in the presence of multiple aerosol layers within the PBL are removed; in this case the correlation coefficients of the fit applied to the three comparisons get values in excess of 0.94 , with the relative bias between the approaches not exceeding $3 \%$. This result testifies that the use of approach (2) allows to circumvent the problems associated with the application of approach (1) in the presence of strong aerosol gradients associated with aerosol layers within the PBL or - after sunset - with the presence of a residual aerosol layer aloft the actual mixed layer, thus allowing unambiguous estimates of the PBL height at any time of the day.

As neither approach (1) nor approach (2) can be considered to have an edge over the other approach, each of them having specific advantages and disadvantages, the possibility of applying these two approaches together is certainly a big plus of the considered ground-based Raman lidar system. In this respect, it is to be pointed out that the data set collected by BASIL during COPS provides a unique collection of data for the study of boundary layer structure and evolution.
Acknowledgements. This research effort was partially supported by the European Commission under the European Fleet for Airborne Research programme of the 7th Framework Programme. We also wish to thank the International Science Steering Committee of the Convective and Orographically-Induced Precipitation Study for financially supporting this activity.

Edited by: D. Cimini

\section{References}

Behrendt, A., Pal, S., Aoshima, F., Bender, M., Blyth, A., Corsmeier, U., Cuesta, J., Dick, G., Dorninger, M., Flamant, C., Di Girolamo, P., Gorgas, T., Huang, Y., Kalthoff, N., Khodayar, S., Mannstein, H., and Wulfmeyer, V.: Observation of Convection Initiation Processes with a Suite of State-of-the-Art Research Instruments during COPS IOP8b, Q. J. Roy. Meteorol. Soc., 137, 81-100, doi:10.1002/qj.758, 2011.

Bhawar, R., Di Girolamo, P., Summa, D., Flamant, C., Althausen, D., Behrendt, A., Kiemle, C., Bosser, P., Cacciani, M., Champollion, C., Di Iorio, T., Engelmann, R., Herold, C., Müller, D., Pal, S., Wirth, M., and Wulfmeyer, V.: The Water Vapour Intercomparison Effort in the Framework of the Convective and Orographically-Induced Precipitation Study: Airborne-toGround-based and airborne-to-airborne Lidar Systems, Q. J. Roy. Meteorol. Soc., 137, 325-348, doi:10.1002/qj.697, 2011

Boers, R., Spinhirne, J. D., and Hart, W. D.: Lidar observations of the fine-scale variability of marine stratocumulus clouds, J. Appl. Meteorol., 27, 797-810, 1988

Bösenberg, J. and Linné, H.: Laser remote sensing of the planetary boundary layer, Meteor. Z., 11, 233-240, 2002.

Brooks, I. M.: Finding boundary layer top: Application of a wavelet covariance transform to lidar backscatter profiles, J. Atmos. Oceanic Technol., 20, 1092-1105, 2003.

Cohn, S. A. and Angevine, W. M.: Boundary layer height and entrainment zone thickness measured by lidars and windprofiling radars, J. Appl. Meteor., 39, 1233-1247, 2000.

Cramer, O. P.: Potential temperature analysis for mountainous terrain, J. Appl. Meteor., 11, 44-50, 1972.

Davis, K. J., Gamage, N., Hagelberg, C. R., Kiemle, C., Lenschow, D. H., and Sullivan, P. P.: An objective method for deriving atmospheric structure from airborne lidar observations, J. Atmos. Oceanic Technol., 17, 1455-1468, 2000.

De Wekker, S. F. J., Kossmann, M., and Fielder, F.: Observations of daytime mixed layer heights over mountainous terrain during the TRACT field campaign. Proc. 12th Symp. on Boundary Layers and Turbulence, Vancouver, BC, Canada, Am. Meteor. Soc., 1, 498-499, 1997.

Di Girolamo, P., Ambrico, P. F., Amodeo, A., Boselli, A., Pappalardo, G., and Spinelli, N.: Aerosol observations by Lidar in the Nocturnal Boundary Layer, Appl. Opt., 38, 4585-4595, doi:10.1364/AO.38.004585, 1999.

Di Girolamo, P., Marchese, R., Whiteman, D. N., and Demoz, B. B.: Rotational Raman Lidar measurements of atmospheric temperature in the UV, Geophys. Res. Lett., 31, L01106, doi:10.1029/2003GL018342, 2004. 
Di Girolamo, P., Behrendt, A., and Wulfmeyer, V.: Spaceborne profiling of atmospheric temperature and particle extinction with pure rotational Raman lidar and of relative humidity in combination with differential absorption lidar: performance simulations, Appl. Opt., 45, 2474-2494, doi:10.1364/AO.45.002474, 2006.

Di Girolamo, P., Summa, D., and Ferretti, R.: Multiparameter Raman Lidar Measurements for the Characterization of a Dry Stratospheric Intrusion Event, J. Atmos. Ocean. Technol., 26, 1742-1762, doi:10.1175/2009JTECHA1253.1, 2009a.

Di Girolamo, P., Summa, D., Lin, R. F., Maestri, T., Rizzi, R., and Masiello, G.: UV Raman lidar measurements of relative humidity for the characterization of cirrus cloud microphysical properties, Atmos. Chem. Phys., 9, 8799-8811, doi:10.5194/acp-9-87992009, 2009b.

Di Girolamo, P., Summa, D., Bhawar, R., Di Iorio, T., Cacciani, M., Veselovskii, I., Dubovik, O., and Kolgotin, A.: Raman lidar observations of a Saharan dust outbreak event: Characterization of the dust optical properties and determination of particle size and microphysical parameters, Atmos. Environ., 50, 66-78, doi:10.1016/j.atmosenv.2011.12.061, 2012a.

Di Girolamo, P., Summa, D., Cacciani, M., Norton, E. G., Peters, G., and Dufournet, Y.: Lidar and radar measurements of the melting layer: observations of dark and bright band phenomena, Atmos. Chem. Phys., 12, 4143-4157, doi:10.5194/acp-12-41432012, 2012b.

Flamant, C., Pelon, J., Flamant, P. H., Durand, P.: Lidar determination of the entrainment zone thickness at the top of the unstable marine atmospheric boundary layer, Bound.-Lay. Meteorol., 83, 247-284, 1997.

Frioud, M., Mitev, V., Matthey, R., Häberli, C., Richner, H., Werner, R., and Vogt, S.: Elevated aerosol stratification above Rhine Valley under strong anticyclonic conditions, Atmos. Environ., 37, 1785-1797, 2003.

Garratt, J. R.: The Atmospheric Boundary Layer, Cambridge Atmospheric and Space Science Series, Cambridge Univ. Press, 335 pp., 1992

Griaznov, V., Veselovskii, I., Di Girolamo, P., Korenskii, M., and Summa, D.: Spatial distribution of doubly scattered polarized laser radiation in the focal plane of a lidar receiver, Appl. Opt., 46, 6821-6830, 2007.

Haeffelin, M., Angelini, F., Morille, Y., Martucci, G., O’Dowd, C. D., Xueref-Rémy, I., Wastine, B., Frey, S., and Sauvage, L.: Evaluation of mixing depth retrievals from automatic profiling lidars and ceilometers inview of future integrated networks in $\mathrm{Eu}-$ rope, Bound.-Lay. Meteorol., 143, 49-75, doi:10.1007/s10546011-9643-z, 2012.

Hägeli, P., Steyn, D. G., and Strawbridge, K. B.: Spatial and temporal variability of mixed-layer depth and entrainment zone thickness, Bound.-Lay. Meteorol., 97, 47-71, 2000.

Hastenrath, S.: Climate Dynamics of the Tropics, Kluwer Academic Publishers, Dordrecht, 488 pp., 1991.

Hayden, K. L., Anlauf, K. G., Hoff, R. M., Strapp, J. W., Bottenheim, J. W., Wiebe, H. A., Froude, F. A., Martin, J. B., Steyn, D. G., and McKendry, I. G.: The Vertical Chemical and Meteorological Structure of the Boundary Layer in the Lower Fraser Valley during Pacific '93', J. Atmos. Environ., 31, 2089-2105, 1997.

Hoff, R. M., Harwood, M., Sheppard, A., Froude, F., and Martin, J. B.: Use of airborne lidar to determine aerosol sources and move- ment in the Lower Fraser Valley (LFV), BC, Atmos. Environ., 31, 2123-2134, 1997.

Hooper, W. P. and Eloranta, E. W.: Lidar measurements of wind in the planetary boundary layer: the method, accuracy and results from joint measurements with radiosonde and Kytoon, J. Climate Appl. Meteorol., 25, 990-1001, 1986.

Kalthoff, Adler, B., Barthlott, C., Corsmeier, U., Mobbs, S., Crewell, S., Trumner, K., Kottmeier, C., Wieser, A., Smith, V., and Di Girolamo, P.: The impact of convergence zones on the initiation of deep convection: A case study from COPS, Atmos. Res., Ed. Elsevier, 93, 680-694, doi:10.1016/j.atmosres.2009.02.010, 2009.

Kottmeier, C., Kalthoff, N., Barthlott, C., Corsmeier, U., Van Baelen, J., Behrendt, A., Behrendt, R., Blyth, A., Coulter, R., Crewell, S., Di Girolamo, P., Dorninger, M., Flamant, C., Foken, T., Hagen, M., Hauck, C., Höller, H., Konow, H., Kunz, M., Mahlke, H., Mobbs, S., Richard, E., Steinacker, R., Weckwerth, T., Wieser, A., and Wulfmeyer, V.: Mechanisms initiating deep convection over complex terrain during COPS, Meteorol. Z., 17, 931-948, 2008.

Maestri, T., Di Girolamo, P., Summa, D., and Rizzi, R.: Clear and cloudy sky investigations using Raman lidar and airborne interferometric measures from the European AQUA Thermodynamic Experiment, Atmos. Res., 97, 157-169, doi:10.1016/j.atmosres.2010.03.020, 2010.

Mallat, S. G. and Hwang, W. L.: Singularity detection and processing with wavelets, IEEE Trans. Inf. Theory, 38, 617-643, 1992.

Martucci, G., Matthey, R., Mitev, V., and Richner, H.: Comparison between backscatter lidar and radiosonde measurements of the diurnal and nocturnal stratification in the lower troposphere, J. Atmos. Ocean. Technol., 24, 1231-1244, 2007.

Martucci, G., Matthey, R., Mitev, V., and Richner, H.: Frequency of boundary-layer-top fluctuations in convective and stable conditions using laser remote sensing, Bound.-Lay. Meteorol., 135, 313-331, 2010.

Matthias, V., Balis, D., Bösenberg, J., Eixmann, R., Iarlori, M., Komguem, L., Mattis, I., Papayannis, A., Pappalardo, G., Perrone, M. R., and Wang, X.: Vertical aerosol distribution over Europe: Statistical analysis of Raman lidar data from 10 European Aerosol Research Lidar Network (EARLINET) stations, J. Geophys. Res., 109, D18201, doi:10.1029/2004JD004638, 2004.

Melfi, S. H., Spinhirne, J. D., Chou, S. H., and Palm, S. P.: Lidar observation of the vertically organized convection in the planetary boundary layer over the ocean, J. Climate Appl. Meteorol., 24, 806-821, 1985.

Menut, L., Flamant, C., Pelon, J., and Flamant, P. H.: Urban boundary layer height determination from lidar measurements over the Paris area, Appl. Opt., 38, 945-954, 1999.

Morille, Y., Haeffelin, M., Drobinski, P., and Pelon, J.: STRAT: An Automated Algorithm to Retrieve the Vertical Structure of the Atmosphere from Single-Channel Lidar Data, J. Atmos. Ocean. Technol., 24, 761-775, 2007.

Oke, T. R.: Boundary Layer Climates, 2nd Edn., 435 pp., Halsted Press, New York, 1988

Pal, S., Behrendt, A., and Wulfmeyer, V.: Elastic-backscatter-lidarbased characterization of the convective boundary layer and investigation of related statistics, Ann. Geophys., 28, 825-847, doi:10.5194/angeo-28-825-2010, 2010. 
Russell, P. B., Uthe, E. E., Ludwig, F. L., and Shaw, N. A.: A comparison of atmospheric structure as observed with monostatic acoustic sounder and lidar techniques, J. Geophys. Res., 79, 5555-5566, 1974.

Seibert, P., Beyrich, F., Gryning, S. E., Joffre, S., Rasmussen, A., and Tercier, P.: Review and Intercomparison of Operational Methods for the Determination of the Mixing Height, Atmos. Environ., 34, 1001-1020, 2000.

Sicard, M., Pérez, C., Rocadembosch, F., Baldasano, J. M., and Garcìa-Vizcaino, D.: Mixed layer determination in the Barcelona coastal area from regular lidar measurements: methods, results and limitations, Bound.-Lay. Meteorol., 119, 135-157, 2006.

Sorbjan, Z.: Structure of the Atmospheric Boundary Layer, Prentice Hall, Englewood Cliffs, N.J. 317 pp., 1989

Steyn, D. G., Baldi, M., and Hoff, R. M.: The detection of mixed layer depth and entrainment zone thickness from lidar backscatter profiles, J. Atmos. Ocean. Technol., 16, 953-959, 1999.

Stull, R. B.: An Introduction to Boundary Layer Meteorology, Dordrecht, Kluwer, 666 pp., 1998.

Van Pul, W. A. J., Holtslag, A. A. M., and Swart, D. P. J.: A comparison of ABL heights inferred routinely from lidar and radiosondes at noontime, Bound.-Lay. Meteorol., 68, 173-191, 1994.
Wulfmeyer, V., Behrendt, A., Bauer, H. S., Kottmeier, C., Corsmeier, U., Blyth, A., Craig, G., Schumann, U., Hagen, M., Crewell, S., Di Girolamo, P., Flamant, C., Miller, M., Montani, A., Mobbs, S., Richard, E., Rotach, M. W., Arpagaus, M., Russchenberg, H., Schlüssel, P., König, M., Gärtner, V., Steinacker, R., Dorninger, M., Turner, D. D., Weckwerth, T., Hense, A., and Simmer, C.: The Convective and Orographically-induced Precipitation Study: A Research and Development Project of the World Weather Research Program for Improving Quantitative Precipitation Forecasting in Low-mountain Regions, B. Am. Meteorol. Soc., 89, 1477-1486, doi:10.1175/2008BAMS2367.1, 2008.

Wulfmeyer, V., Behrendt, A., Kottmeier, C., Corsmeier, U., Barthlott, C., Craig, G. C., Hagen, M., Althausen, D., Aoshima, F., Arpagaus, M., Bauer, H. S., Bennett, L., Blyth, A., Brandau, C., Champollion, C., Crewell, S., Dick, G., Di Girolamo, P., Dorninger, M., Dufournet, Y., Eigenmann, R., Engelmann, R., Flamant, C., Foken, T., Gorgas, T., Grzeschik, M., Handwerker, J., Hauck, C., Höller, H., Junkermann, W., Kalthoff, N., Kiemle, C., Klink, S., König, M., Krauss, L., Long, C. N., Madonna, F., Mobbs, S., Neininger, B., Pal, S., Peters, G., Pigeon, G., Richard, E., Rotach, M. W., Russchenberg, H., Schwitalla, T., Smith, V., Steinacker, R., Trentmann, J., Turner, D. D., van Baelen, J., Vogt, S., Volkert, H., Weckwerth, T., Wernli, H., Wieser, A., and Wirth, M.: The Convective and Orographically Induced Precipitation Study (COPS): The Scientific Strategy, the Field Phase, and Research Highlights, Q. J. Roy. Meteorol. Soc., 137, 3-30, doi:10.1002/qj.752, 2011. 